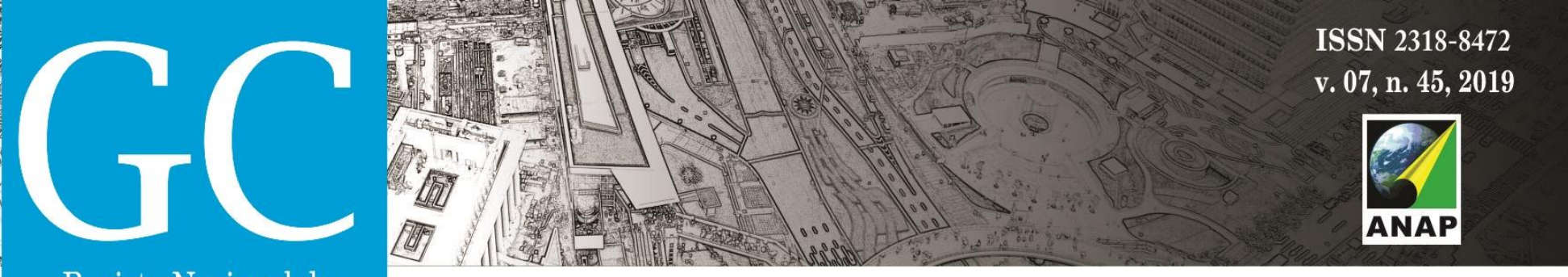

Revista Nacional de

Gerenciamento de Cidades

\title{
Análise da sustentabilidade na mobilidade urbana do município de Vinhedo
}

Analysis of sustainability in urban mobility in the municipality of Vinhedo

Análisis de la sostenibilidad en la movilidad urbana del municipio de Vinhedo

Luiz Henrique Vieira da Silva

Mestrando em Sustentabilidade e bolsista Capes Modalidade I, Pontifícia Universidade Católica de Campinas - PUC-Campinas, Brasil

luiz.hvs@puccampinas.edu.br

Samuel Carvalho De Benedicto

Professor Titular e Pesquisador do Centro de Economia e Administração da Pontifícia Universidade Católica de Campinas - PUC-Campinas, Brasil.

samuel.benedicto@puccampinas.edu.br 


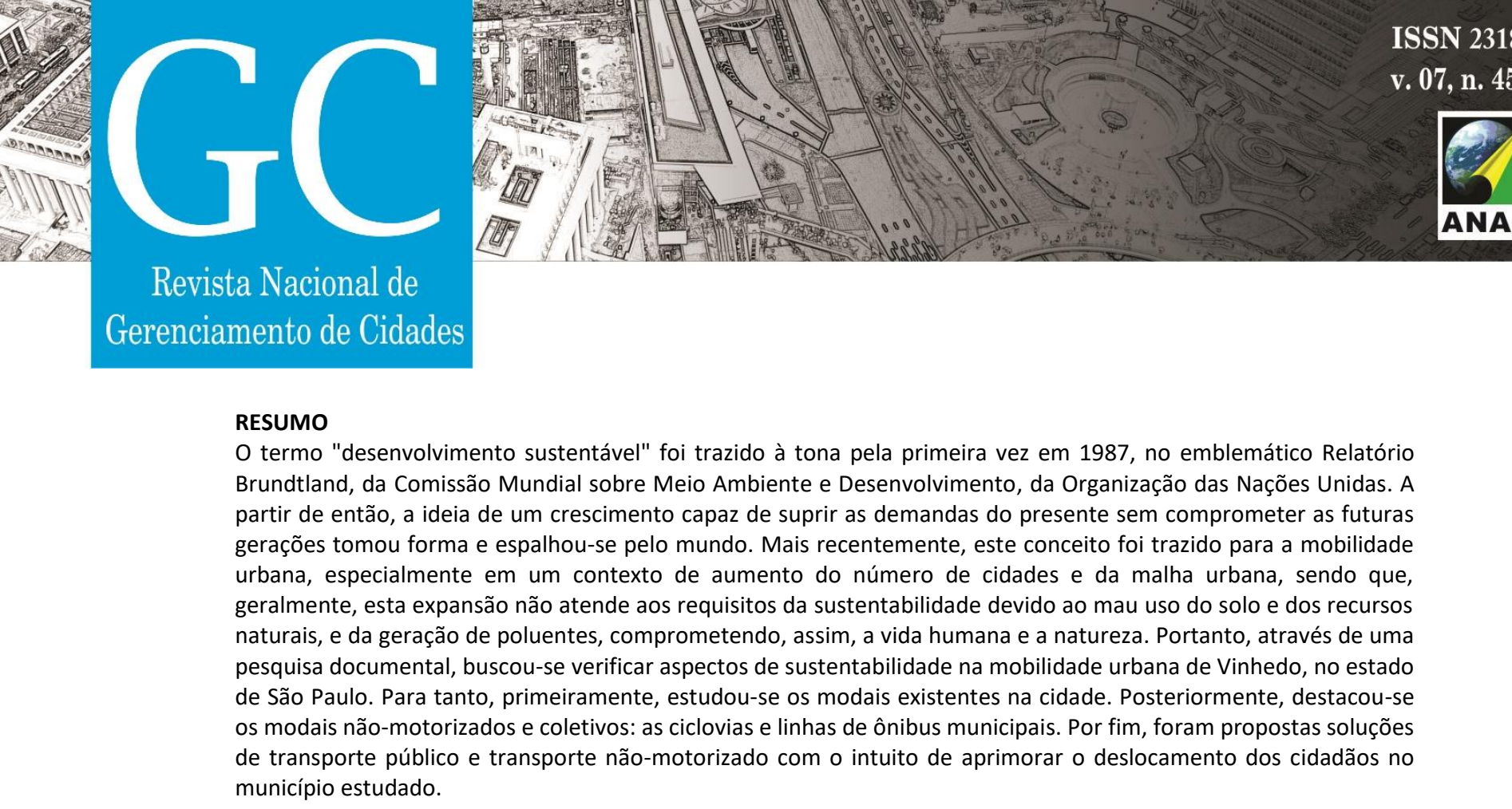

PALAVRAS-CHAVE: Mobilidade Urbana, Mobilidade Urbana Sustentável, Sustentabilidade, Vinhedo.

\section{SUMMARY}

The term "sustainable development" was first brought to the surface in 1987 in the landmark Brundtland Report of the United Nations World Commission on Environment and Development. From then on, the idea of growth capable of meeting the demands of the present without compromising future generations has taken shape and spread throughout the world. More recently, this concept has been brought to urban mobility, especially in a context of increasing numbers of cities and the urban network, and this expansion generally does not meet the requirements of sustainability due to misuse of land and natural resources, and the generation of pollutants, thus compromising human life and nature. Therefore, through documentary research, it was sought to verify sustainability aspects in the urban mobility of Vinhedo, in the state of São Paulo. To do so, first, we studied the existing modalities in the city. Subsequently, the non-motorized and collective modes were highlighted: the bicycle lanes and municipal bus lines. Finally, solutions were proposed for public transport and non-motorized transport with the aim of improving the movement of citizens in the municipality studied.

KEY WORDS: Urban Mobility, Sustainable Urban Mobility, Sustainability, Vinhedo.

\section{RESUMEN}

El término "desarrollo sostenible" fue lanzado a la luz por primera vez en 1987, en el emblemático Informe Brundtland, de la Comisión Mundial sobre Medio Ambiente y Desarrollo, de la Organización de las Naciones Unidas. A partir de entonces, la idea de un crecimiento capaz de suplir las demandas del presente sin comprometer a las futuras generaciones tomó forma y se extendió por el mundo. Más recientemente, este concepto fue traído a la movilidad urbana, especialmente en un contexto de aumento del número de ciudades y de la malla urbana, siendo que generalmente esta expansión no atiende a los requisitos de la sostenibilidad debido al mal uso del suelo y de los recursos naturales, y de la generación de contaminantes, comprometiendo así la vida humana y la naturaleza. Por lo tanto, a través de una investigación documental, se buscó verificar aspectos de sustentabilidad en la movilidad urbana de Vinhedo, en el estado de São Paulo. Para ello, primero, se estudiaron los modales existentes en la ciudad. Posteriormente, se destacaron los modales no motorizados y colectivos: las ciclovías y líneas de autobuses municipales. Por último, se propusieron soluciones de transporte público y transporte no motorizado con el fin de mejorar el desplazamiento de los ciudadanos en el municipio estudiado.

PALABRAS CLAVE: Mobilidade Urbana, Mobilidade Urbana Sustentável, Sustentabilidade, Vinhedo. 


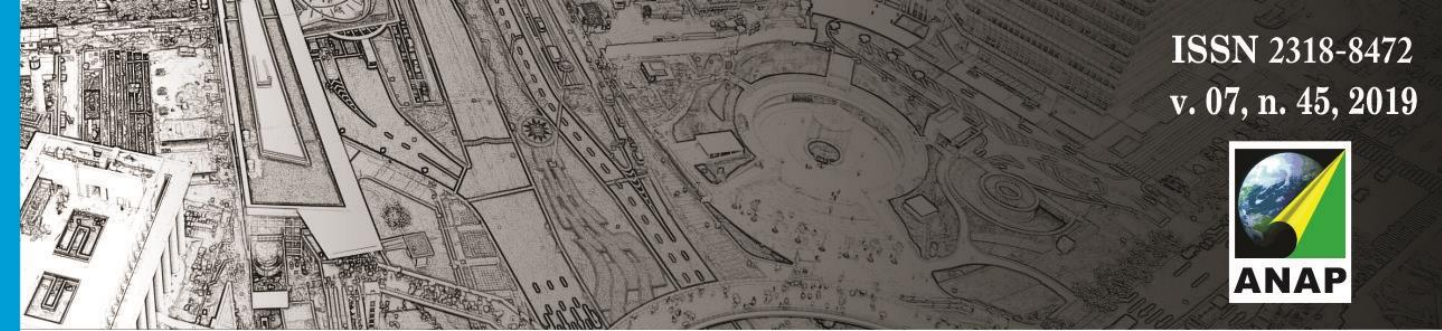

Revista Nacional de

Gerenciamento de Cidades

\section{Introdução}

No ano de 1987, em meio aos debates a nível global acerca das questões ambientais, o Relatório "Nosso Futuro Comum", elaborado pela Comissão Mundial sobre o Meio Ambiente e o Desenvolvimento (WCED), trouxe pela primeira vez à tona o termo "desenvolvimento sustentável", expandindo o conceito para outras dimensões, além da ambiental, em uma época marcada pelo neoliberalismo (NASCIMENTO, 2012). Neste documento, também chamado de Relatório Brundtland, em homenagem à ministra norueguesa e presidenta da WCED, Gro Harlem Brundtland, idealizadora desta declaração, o desenvolvimento sustentável é descrito como aquele que "atende às necessidades do presente sem comprometer a possibilidade de as gerações futuras atenderem suas próprias necessidades" (ONU, 1987).

Por conseguinte, entende-se que este termo está intimamente ligado à capacidade de, como o próprio nome indica, sustentação, ou seja, permitir que exista uma continuidade, seja pela aplicação inteligente dos recursos, seja pela capacidade de preservá-los ou pela garantia da vida com qualidade (ABDALA; PASQUALETTO, 2013).

Neste sentido, surge a ideia de mobilidade urbana sustentável, aliando os conceitos do desenvolvimento sustentável para a ótica dos transportes no meio urbano. Ainda que seja difícil estabelecer uma definição exata para tal, de acordo com o extinto Ministério das Cidades, órgão que tinha, por competências, aspectos ligados à política de desenvolvimento urbano no Brasil, entende-se por mobilidade urbana sustentável

...a reunião das políticas de transporte e de circulação, e integrada com a política de desenvolvimento urbano, com a finalidade de proporcionar o acesso amplo e democrático ao espaço urbano, priorizando os modos de transporte coletivo e os não-motorizados, de forma segura, socialmente inclusiva e sustentável (CIDADES, 2014).

Sendo assim, é possível pormenorizar cada parte desta definição e, a partir disso, desenvolver três linhas de pensamento:

- "a reunião das políticas de transporte e de circulação, e integrada com a política de desenvolvimento urbano": a mobilidade urbana sustentável não se restringe ao transporte, sendo também, o complexo conjunto de calçadas, passarelas, áreas públicas, que compõem a circulação dos pedestres e veículos e o desenvolvimento da cidade;

- "com a finalidade de proporcionar o acesso amplo e democrático ao espaço urbano": é necessário garantir que o espaço urbano seja democrático, ou seja, permita que todos possam acessá-lo igualmente: pessoas com deficiência, idosos, crianças, veículos automotores e veículos não-motorizados, etc.;

- "priorizando os modos de transporte coletivo e os não-motorizados, de forma segura, socialmente inclusiva e sustentável": deve-se priorizar os modais de transporte coletivo, em detrimento dos veículos particulares e, também, aqueles não-motorizados, garantindo assim, eficiência na utilização do espaço público, pois os coletivos são capazes de deslocar mais pessoas 


\section{Revista Nacional de}

Gerenciamento de Cidades

ocupando menor espaço, e uma redução na poluição, em congestionamentos, resultando em qualidade de vida e desenvolvimento da cidade.

Diante do exposto, surge a necessidade de verificar como as políticas públicas de mobilidade urbana têm se desdobrado no contexto das grandes e médias cidades do Brasil. No presente estudo, será abordado o município de Vinhedo.

Esta cidade está localizada na Região Metropolitana de Campinas (RMC) ${ }^{1}$, distando 75 quilômetros da capital paulista. Seu pequeno território de $81,60 \mathrm{~km}^{2}$ abriga uma população estimada, segundo dados do Instituto Brasileiro de Geografia e Estatística (IBGE) e da Fundação Seade, de 73.550 habitantes, conferindo, então, uma densidade demográfica de mais de 870 habitantes por $\mathrm{km}^{2}$ ao município, sendo assim, a quarta cidade mais povoada da Região Metropolitana de Campinas, que compreende 20 municípios.

Vinhedo é considerada uma "cidade dormitório", termo designado para municípios que servem de moradia para trabalhadores da cidade-núcleo da região. Esta característica é acentuada pelo fato de estar muito bem posicionada no eixo São Paulo-Campinas, servida por duas das principais rodovias do estado: Bandeirantes (SP-348) e Anhanguera (SP-330), que interligam a capital paulista ao interior do estado.

Sendo assim, pela alta concentração de empresas e negócios em um raio de no máximo 80 quilômetros, a cidade é procurada por pessoas que procuram instalarem-se no conforto de uma pequena cidade, com as facilidades da proximidade com os grandes centros urbanos e em local atrativo pela crescente geração de empregos e pelos serviços públicos de qualidade.

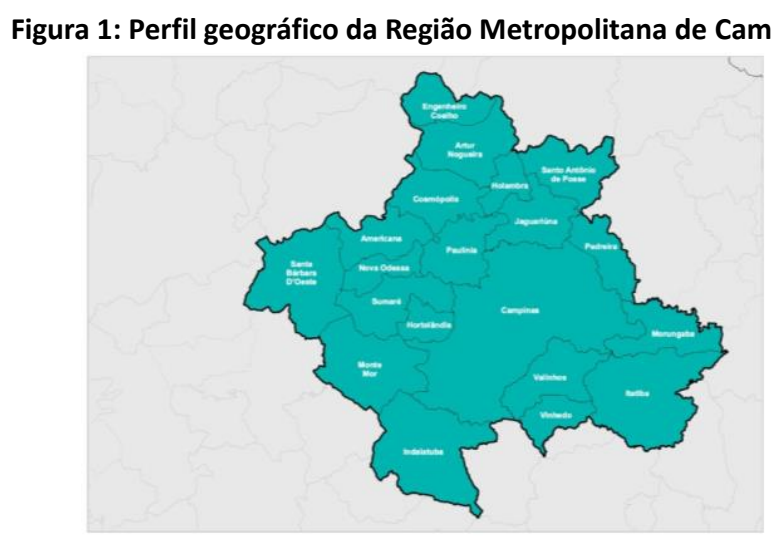

Fonte: Emplasa, GIP/CDI (2019).

A população que se deslocou à cidade trouxe consigo um aumento na frota de veículos, fazendo com que o número de automóveis chegasse à marca de 37.804 no ano de 2014. Somando-se às

\footnotetext{
${ }^{1}$ Criada em 2000, a Região Metropolitana de Campinas é integrada pelos seguintes municípios: Americana, Artur Nogueira, Campinas, Cosmópolis, Engenheiro Coelho, Holambra, Hortolândia, Indaiatuba, Itatiba, Jaguariúna, Monte Mor, Morungaba, Nova Odessa, Paulínia, Pedreira, Santa Bárbara d'Oeste, Santo Antônio de Posse, Sumaré, Valinhos e Vinhedo.
} 


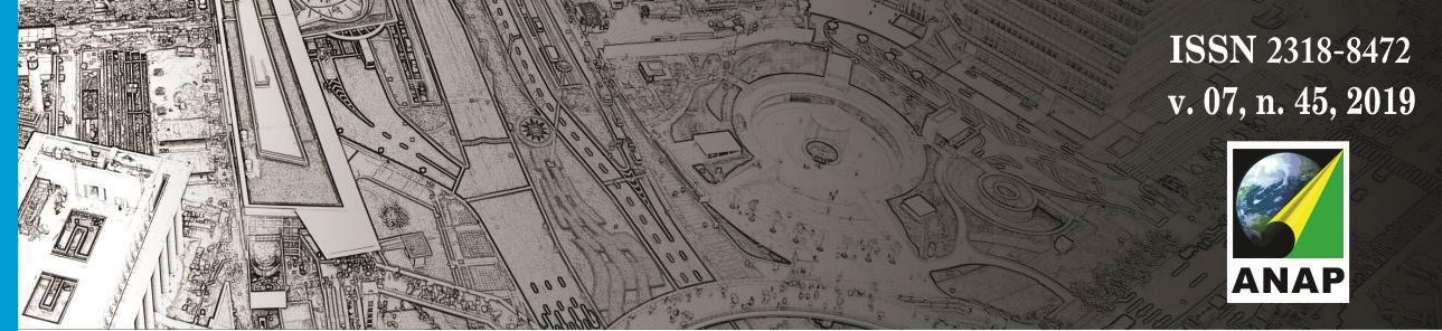

Revista Nacional de

Gerenciamento de Cidades

outras categorias - caminhonetes, utilitários, motocicletas, caminhões - o número salta para 58.391 para um município que, na época, abrigava pouco mais de 67 mil habitantes (IBGE, 2015). Este resultado é ainda mais alarmante se destacarmos o fato de que não há alternativas de transporte sustentável na cidade, como ciclovias funcionais, linhas de bonde, VLTs e afins, sendo o ônibus a única solução para transporte coletivo. Em horários de pico, especialmente nas ligações com as cidades vizinhas e com as rodovias, os congestionamentos estendem-se cada vez mais, favorecendo problemas como a poluição atmosférica pelo $\mathrm{CO}_{2}$ emitido pelos automóveis (e, consequentemente, de problemas respiratórios) e o sedentarismo.

Porém, não apenas este município paulista apresenta um crescimento no número de veículos automotores, pois o mesmo reproduz uma tendência nacional: entre os censos demográficos de 2000 e 2010 houve um aumento de $11,8 \%$ na população brasileira, enquanto que a frota de veículos automotores cresceu incríveis 138,6\% no mesmo período (METRÓPOLES, 2013). Devese dar o devido destaque ao processo de urbanização do Brasil nos últimos 50 anos que ainda apresenta suas consequências e, mais recentemente, ao crescimento econômico brasileiro. De acordo com Boareto (2008),

...podemos afirmar que a atual política de mobilidade urbana reflete uma visão de cidade, não sendo resultado da falta de planejamento ou da visão distorcida daqueles que não percebem os atuais problemas decorrentes deste modelo ou não se conscientizaram ainda das vantagens do transporte coletivo ou não motorizado.

Depreende-se, então, que em muitas cidades acontec

e a reprodução de um modo de pensar fortemente influenciado pela expansão do automóvel, sinônimo de luxo e superioridade, enquanto que as soluções baseadas no transporte público, coletivo e sustentável tornaram-se ideias pouco adotadas por governos e encurraladas apenas a projetos universitários ou protótipos espalhados pelo país, sem grande adesão, ainda que isto venha se alterando nos últimos anos.

Ainda assim, é imprescindível afirmar que a busca por um "sistema de mobilidade mais igualitário do ponto de vista social, com sustentação financeira e ao mesmo tempo sem excluir os mais pobres" é obrigação dos políticos e administradores públicos (IPEA, 2016).

O Artigo 182 da Constituição Federal de 1988, em seu primeiro parágrafo, dita: "O plano diretor, aprovado pela Câmara Municipal, obrigatório para cidades com mais de vinte mil habitantes, é o instrumento básico da política de desenvolvimento e de expansão urbana" (BRASIL, 1988). Ainda, de acordo com Villaça (1995), plano diretor é

...um plano que, a partir de um diagnóstico científico da realidade física, social, econômica, política e administrativa da cidade, do município e de sua região, apresentaria um conjunto de propostas para o futuro desenvolvimento socioeconômico e futura organização espacial dos usos do solo urbano, das redes de infraestrutura e de elementos fundamentais da 


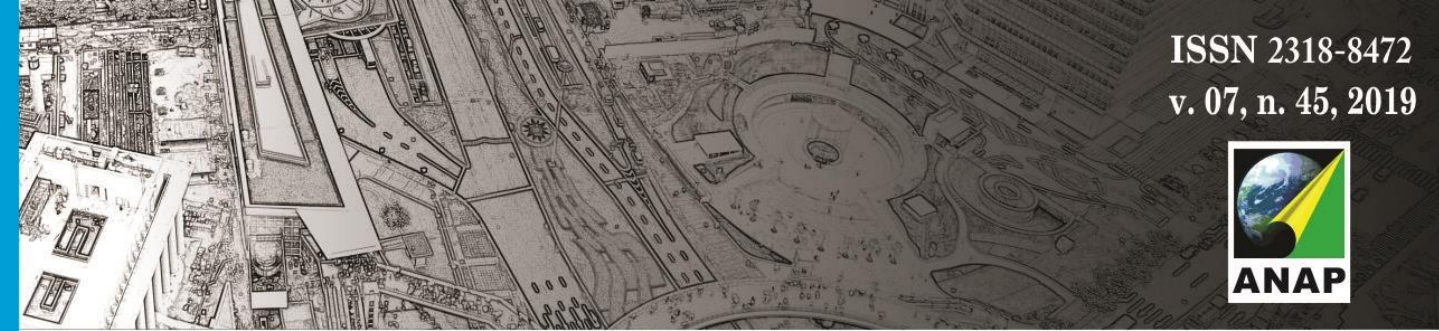

Revista Nacional de

Gerenciamento de Cidades

estrutura urbana, para a cidade e para o município, propostas estas definidas para curto, médio e longo prazos, e aprovadas por lei municipal.

Nesse sentido, entende-se que este marco na organização municipal deva privilegiar os interesses comuns da população, bem como seu desenvolvimento de maneira sustentável e inteligente de acordo com as peculiaridades de cada município.

Porém, o Plano Diretor de Vinhedo, promulgado Lei Complementar № 66, de 17 de Janeiro de 2007, pouco foi seguido no tocante às soluções de mobilidade urbana, ainda que exista uma menção clara ao Plano de Mobilidade Urbana (VINHEDO, 2007). Há uma crescente em engarrafamentos nas principais vias que cortam a cidade, especialmente levando-se em conta sua posição geográfica, que faz Vinhedo receber automóveis de outros municípios, somando-se ao número de veículos que já trafegam naturalmente em suas ruas e avenidas. Esta situação, aliada a um número limitado de linhas de ônibus e circulares, sem alternativas de transporte público ou não motorizado (excetuando-se o modal a pé e apenas cinco quilômetros de ciclovias), cria uma bolha que gera entraves ao crescimento da cidade e ao desenvolvimento sustentável.

Até o presente momento, debate-se o Plano Diretor com a comunidade, através de diversas reuniões nos bairros, com a eleição de representantes e com a discussão na Câmara Municipal para que este documento, que é um instrumento indispensável "para a implantação da política de desenvolvimento urbano, norteando a ação dos agentes públicos e privados" (ABNT, 1999), tenha a participação popular como base de sua formulação. Sendo assim, este estudo surge como mais um apoiador do discurso da necessidade de reformas na mobilidade urbana de Vinhedo a fim de proporcionar um crescimento sustentável e inteligente da malha urbana, ocupando o solo racionalmente e fornecendo, através de políticas públicas, meios de transporte acessíveis a toda população, com o menor nível de poluição possível e capazes de serem um modelo para outras cidades pequenas e médias do Brasil que sofrem, ou sofrerão, os mesmos problemas futuramente, decorrentes do fenômeno do crescimento urbano que se mostra maior a cada década.

Um ponto positivo neste aspecto é que o município está elaborando um Plano Municipal de Mobilidade Urbana, que, segundo a Prefeitura, proporá alternativas para o transporte coletivo e resolverá o problema dos congestionamentos, citados anteriormente. Porém, como o mesmo ainda está em fase de elaboração, ainda que já conte com o apoio da Agência Metropolitana de Campinas (Agemcamp) e do Fundo Metropolitano de Campinas (FUNDOCAMP) para o início das obras, será necessário aguardar para que o mesmo implemente, de fato, políticas públicas de mobilidade urbana, atendendo às exigências previstas na Constituição Federal, que trata o transporte público como direito social, tal qual a educação, a saúde, a alimentação, o trabalho, a moradia, o lazer, a segurança, a previdência social, a proteção à maternidade e à infância, e a assistência aos desamparados (BRASIL, 1988) e no Estatuto da Cidade, que garante 


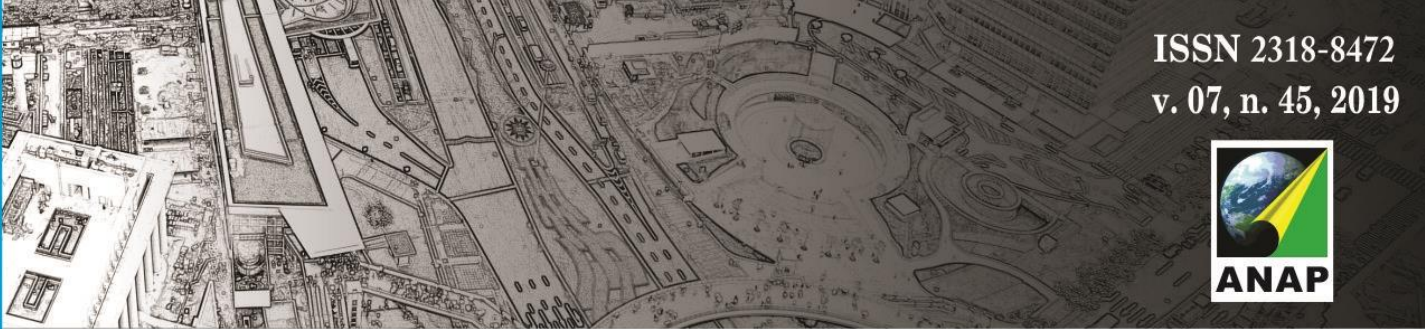

Revista Nacional de

Gerenciamento de Cidades

...o direito a cidades sustentáveis, entendido como o direito à terra urbana, à moradia, ao saneamento ambiental, à infraestrutura urbana, ao transporte e aos serviços públicos, ao trabalho e ao lazer, para as presentes e futuras gerações (BRASIL, 2001).

A pressão por crescimento da cidade, aliada ao contexto de área metropolitana, atrativa de negócios e pessoas, acaba influindo na ocupação do solo e de áreas de preservação ambiental, ainda que em menor escala comparada a metrópoles como São Paulo ou Campinas. Mesmo assim, há zonas de conurbação e a mancha urbana expande-se cada vez, com a criação de loteamentos, novas ruas e avenidas e, especialmente em Vinhedo, de condomínios.

Este modelo de crescimento, portanto, é quase que substancialmente embasado no automóvel particular, desconsiderando soluções em nível municipal e metropolitano de alternativas sustentáveis e coletivas de mobilidade, altamente benéficas a curto, médio e longo prazos, tanto para o desenvolvimento local quanto para a saúde e a qualidade de vida dos munícipes e apostando em uma dinâmica exclusivamente voltada ao capital como expressão ultraliberal do pós-fordismo (CRUZ; FONSECA, 2018).

Esta imagem de crescimento urbano não se restringe apenas ao Brasil, pois é uma tendência mundial, que observa os números de manchas urbanas multiplicando-se, especialmente nas últimas décadas. De acordo com a Organização das Nações Unidas (2012), o Brasil deverá concentrar pouco menos que $90 \%$ de sua população em cidades até o final desta década, aumentando a necessidade de sistemas eficientes de transporte coletivo, ligando os centros às periferias, visto que as cidades brasileiras "se expandem por áreas distantes e desconectadas da mancha urbana, onde o custo da terra é mais barato" (EMBARQ, 2014).

No Quadro 1, estão dispostos alguns dos principais pontos referentes à mobilidade urbana (ou "transportes", termo utilizado até o início do Século) no Brasil.

Quadro 1: Principais avanços na mobilidade urbana do Brasil

\begin{tabular}{|c|c|}
\hline Evento & Ano \\
\hline Constituição aponta um direcionamento dos esforços para o transporte rodoviário & 1934 \\
\hline Introdução da indústria automobilística no Brasil & 1956 \\
\hline Constituição Federal considera a mobilidade um direito social & 1988 \\
\hline Estatuto das Cidades, instituído pela Lei n.10.257/01 & 2001 \\
\hline PAC Mobilidade Grandes Cidades e PAC Mobilidade Médias Cidades & 2009 \\
\hline Política Nacional de Mobilidade Urbana (PNMU), instituída pela Lei n.12.587/2012 & 2012 \\
\hline
\end{tabular}

Fonte: Elaborado pelos autores, com base em Rubim e Leitão (2013).

Depreende-se, então, que o acesso ao transporte faz-se indispensável. Porém, muitas vezes esta necessidade é vista como secundária, ignorando as consequências de se negligenciar o transporte, que recaem à população e geram externalidades em um crescimento irracional e de baixa eficiência para as cidades. Com o crescimento de áreas periféricas altamente dependentes dos centros comerciais e dos polos empregatícios e com soluções de transporte reduzidas ao 


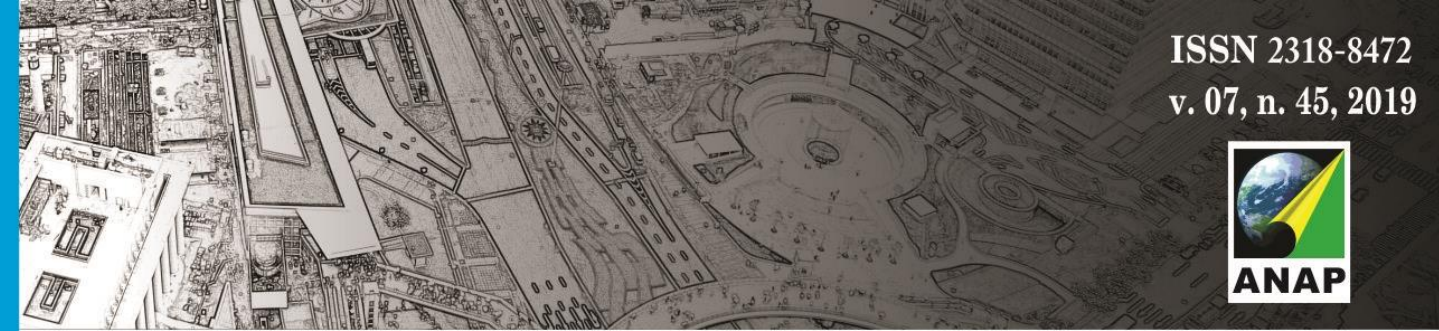

Revista Nacional de

Gerenciamento de Cidades

automóvel particular, não tardam a aparecer problemas urbanos como congestionamentos, acidentes de trânsito, poluição e problemas de saúde pública como o sedentarismo e o estresse. No município em questão, por exemplo, o problema torna-se ainda mais eminente por alguns fatores:

- A explosão no crescimento de veículos automotores em poucos anos, conforme já abordado acima;

- A cidade estar localizada na Região Metropolitana de Campinas, a nona região metropolitana mais populosa do Brasil, fazendo do município um local de grande fluxo de veículos, especialmente se for levado em conta o fato de que Vinhedo está estrategicamente posicionada entre Campinas e Jundiaí, onde o deslocamento de pessoas entre os municípios acontece na grande maioria mediante o automóvel;

- Vinhedo é cortada por duas das principais rodovias do Estado: Bandeirantes (SP-348) e Anhanguera (SP-330). A praça de pedágio da rodovia Anhanguera encontra-se na cidade, fazendo com que uma de suas principais avenidas, a histórica Estrada da Boiada, seja uma rota de fuga, gerando grandes congestionamentos nos horários de pico;

Sendo assim, a fim de romper com este modelo de desenvolvimento baseado no fordismo, que perdurou durante praticamente todo o século XX, soluções sustentáveis e de baixo impacto no meio ambiente tornam-se cada vez mais importantes. Nas cidades brasileiras, algumas experiências bem sucedidas impulsionam gestores públicos, urbanistas e ecologistas a se dedicarem cada vez mais às mudanças nas agendas governamentais em prol do crescimento sustentável, por meio do uso correto do solo, transportes públicos e não motorizados e adequação de ruas, avenidas e até mesmo bairros inteiros para a convivência e a prática de esportes e atividades ao ar livre.

Este trabalho foi desenvolvido mediante a preocupação com um problema crescente e, à primeira vista, de difícil solução, não somente para o município estudado, mas, também, para muitas pequenas e médias cidades brasileiras: a mobilidade urbana deficitária. Portanto, o tema foi escolhido para tratar da necessidade de uma emergência em políticas públicas voltadas ao desenvolvimento sustentável municipal, aliando investimentos em infraestrutura e transportes públicos, não motorizados e alternativos ao transporte particular pelo automóvel.

\section{Objetivos}

O objetivo deste trabalho é identificar as práticas sustentáveis na mobilidade urbana no município de Vinhedo, Estado de São Paulo, detectando-as nos modais existentes atualmente, a fim de gerar um retorno à sociedade e aos órgãos públicos municipais ligados às temáticas de sustentabilidade, planejamento e mobilidade urbana. Com isso, será possível incrementar a qualidade de vida da população e permitir a prosperidade da cidade com base em padrões sustentáveis de desenvolvimento e operacionalização inteligente, inovadora e responsável de todos os modais de transporte disponíveis no local. 


\section{Revista Nacional de}

Gerenciamento de Cidades

\section{Metodologia do estudo}

Este estudo é, quanto à abordagem do problema, qualitativo. Segundo Gil (2008) a pesquisa qualitativa busca a explicação sistemática de fatos que ocorrem no contexto social que, geralmente, se encontra relacionado a uma multiplicidade de variáveis.

Quanto aos procedimentos, optou-se por realizar uma pesquisa documental, que utiliza "materiais que não receberam ainda um tratamento analítico, ou que ainda podem ser reelaborados de acordo com os objetos da pesquisa" (GIL, 2002, p. 45), como os itinerários das linhas de ônibus urbanos de Vinhedo e a legislação vigente sobre o assunto, ambos disponíveis à população.

Para a elaboração dos dois mapas, utilizou o software Google Earth, a fim de dispor as rotas das ciclofaixas e, também, as informações dos itinerários de ida e volta dos ônibus urbanos.

Finalmente, a análise de conteúdo foi eleita como técnica de análise dos dados coletados. Nos últimos anos, a análise de conteúdo vem tendo destaque entre os métodos qualitativos e ganhando legitimidade. A importância da análise de conteúdo para os estudos organizacionais é cada vez maior e tem evoluído em virtude da preocupação com o rigor científico e a profundidade das pesquisas (MOZZATO; GRZYBOVSKI, 2011).

\section{Resultados e discussão}

No município de Vinhedo, alternativas ao transporte individual são praticáveis - e necessárias devido a uma série de fatores. Alguns destes pontos são destacados a seguir:

○ pequena extensão territorial e o também pequeno perímetro urbano, facilitando a aplicação na maioria de suas áreas urbanas;

- densidade demográfica em processo de acentuação, ao mesmo passo em que o número de veículos automotores particulares cresce, demandando soluções em mobilidade urbana urgentemente;

- respaldo garantido por Lei, visto que o Plano Diretor vigente aponta neste sentido como será explanado;

- alto capital arrecadado e repassado ao município.

Outro fator de grande importância e contribuição para a implantação de um sistema de transporte sustentável na cidade é o fato de Vinhedo ser integrante do Programa Município VerdeAzul, ou PMVA, de iniciativa do Governo do Estado de São Paulo. Esta política pública tem como intuito "estimular e auxiliar as prefeituras paulistas na elaboração e execução de suas políticas públicas estratégicas para o desenvolvimento sustentável do estado de São Paulo". Ao final, o município participante recebe o Fundo Estadual de Controle da Poluição - FECOP: mais um incentivo para a adesão ao Programa. 


\section{Revista Nacional de}

Gerenciamento de Cidades

Segundo o Governo estadual, existem dez áreas de atenção neste Programa, a saber: Esgoto Tratado, Resíduos Sólidos, Biodiversidade, Arborização Urbana, Educação Ambiental, Cidade Sustentável, Gestão das Águas, Qualidade do Ar, Estrutura Ambiental e Conselho Ambiental. 0 sistema de transporte sustentável estaria incluso nos quesitos "Cidade Sustentável", "Qualidade

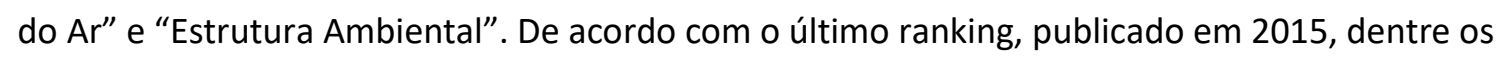
645 municípios paulistas, Vinhedo conseguiu a 48a posição, sendo assim, destaque no cumprimento das diretrizes propostas (VERDEAZUL, 2015).

Ainda assim, analisando o Plano Diretor do município (que é um dos poucos elaborados no Brasil, ainda que o primeiro parágrafo do artigo 182 da Constituição Federal determine às cidades com mais de 20 mil habitantes que o elaborem), é evidente que existe certa "timidez" ao tratar dos veículos não motorizados e de alternativas ao transporte via automóvel particular. Este Plano, promulgado em 2007 e vigente até hoje, no que tange aos temas "mobilidade urbana" e "transportes", pauta-se basicamente por quatro modais: carro, ônibus, bicicleta e pedestre, nesta ordem de importância e visando a compatibilização entre estes modos de transporte. Nele, foram traçados planos como a "reestruturação do sistema viário com vistas à melhoria da circulação e à compatibilização dos diversos modos de transportes priorizando a circulação e o conforto de pedestres e ciclistas, bem como o transporte coletivo" (VINHEDO, 2007), incentivando a criação de ciclovias, estacionamentos e bicicletários.

$\mathrm{Na}$ cidade, pouco foi feito nesse sentido, como pode ser observado na Figura 1, em que o tracejado em vermelho representa as duas únicas ciclovias do município, totalizando 5,5km:

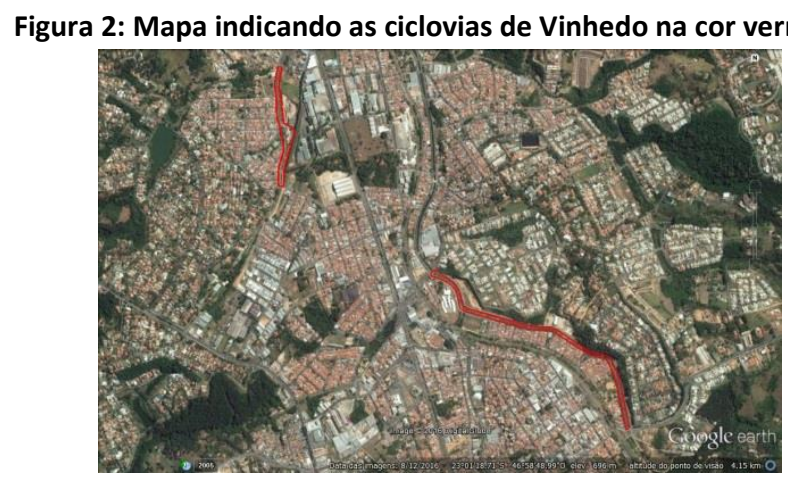

Fonte: Elaborado pelos autores.

A questão das ciclovias foi tratada primeiramente em Vinhedo pela Lei municipal no 2224, que "dispõe sobre a destinação de espaços para ciclovias no município de Vinhedo, e dá outras providências".

À época, optou-se pela obrigatoriedade de demarcação de espaços para ciclovias nas avenidas construídas a partir da promulgação da lei, e que, nas avenidas já existentes e de acesso aos parques públicos do Município, a demarcação de ciclofaixas, destinadas aos usuários nos sábados e domingos, também se fez necessária (VINHEDO, 1995). 


\section{Revista Nacional de}

Gerenciamento de Cidades

É importante ressaltar que, neste caso, não existe uma lógica de interação entre os trajetos de bicicleta e locais de grande concentração populacional ou interesse econômico, como o Centro e o Distrito Industrial. As mesmas são destinadas ao passeio e à prática da pedalada como lazer, e não de maneira funcional, como um instrumento de integração de modais.

Finalmente, destaca-se que a inexistência de bicicletários, ligação entre as ciclovias e as linhas de ônibus e penetração dos trajetos de veículos não motorizados na região central e nos bairros populosos é um desestímulo à prática da pedalada.

Tratando-se dos ônibus urbanos, em Vinhedo, estes são de concessão da empresa Rápido Campinas, do grupo Rápido Luxo Campinas. Atualmente, existem 11 linhas que integram o subsistema urbano, e 12 linhas do subsistema suburbano, sendo 9 linhas metropolitanas, que interligam o município à vizinha Valinhos e a Campinas, pela EMTU, 2 linhas de responsabilidade da Artesp, fazendo o trajeto à vizinha Louveira e a Jundiaí, e 1 linha que transporta os passageiros de Vinhedo ao bairro Santo Antônio, em Louveira.

Dos ônibus que circulam no município, a frota que atende os 11 itinerários contempla 15 veículos, discriminados a seguir, na Tabela 1, que contém as informações do ano de fabricação dos veículos e, também, se há - ou não - acessibilidade nos ônibus das respectivas linhas.

Tabela 1: Pormenorização das linhas de ônibus urbanos de Vinhedo

\begin{tabular}{ccccc}
\hline Linha & Quantidade de ônibus & Ano de fabricação dos veículos & Acessibilidade \\
\hline 401 & 01 & 2012 & Sim \\
402 & 01 & 2008 & Não \\
403 & 01 & 2012 & Sim \\
404 & 01 & 2008 & Não \\
405 & 01 & 2008 & Não \\
406 & 03 & 2012 & Sim \\
407 & 01 & 2012 & Sim \\
408 & 01 & 2009 & Sim \\
409 & 03 & 2012 & Sim \\
410 & 01 & 2008 & Não \\
411 & 01 & 2008 & Não \\
\hline
\end{tabular}

Fonte: Elaborado pelos autores com base em Vinhedo (2019).

A cidade conta com dois terminais rodoviários: Terminal Rodoviário Antônio Zechin e Terminal Rodoviário Verônica Briski Von Zuben. O primeiro localiza-se próximo ao Centro e realiza o maior número de embarques, além de receber, também, o maior número de passageiros. Enquanto isso, o segundo encontra-se no bairro Capela, grande aglomerado populacional distante aproximadamente 5 quilômetros da região central do município, destarte, de grande importância para a integração desta parte da cidade com o Centro e, também, com a região.

Porém, ainda que a malha tenha se expandido recentemente, percebe-se que existem carências neste modal. Segundo a Secretaria de Transporte e Defesa Social do município, em 2013 as 
Revista Nacional de

Gerenciamento de Cidades

linhas de ônibus foram expandidas para garantir economia de tempo e maior cobertura. Ainda assim, loteamentos periféricos recentemente criados, como o Jardim Arco Iris, ainda não são contemplados com o serviço, perpetuando condições sociais de pobreza e marginalização.

Esta lógica deve-se ao crescimento da cidade, que cria vazios, teoricamente dependentes dos meios de transporte públicos para se interligarem aos centros comerciais. A tendência vista em algumas cidades é a de impulsionar o crescimento populacional em regiões próximas a sistemas de transporte coletivo, incentivando a construção de edifícios e, consequentemente, o aumento da população, em áreas próximas a estações, paradas e linhas de transporte coletivo, como no caso da capital paulista (SÃO PAULO, 2014). É imprescindível pensar no desenvolvimento das cidades não esquecendo-se da mobilidade, especialmente em contextos metropolitanos, onde os municípios tendem à conurbação e crescem demasiadamente em questão de poucos anos. No caso vinhedense, observa-se que o crescimento populacional e da malha urbana foi mais acelerado do que a expansão das linhas de ônibus, carecendo de soluções de grande impacto para a mobilidade urbana e favorecendo a lógica do automóvel particular.

A seguir, há uma breve descrição das linhas municipais de ônibus e, na Figura 2, há os traçados das respectivas linhas.

○ Linha 401 | Caixa D’Água: faz a ligação da Rodoviária com o Centro e com a zona rural próxima ao bairro Caixa d'Água, no leste do município. A concentração da mancha urbana é bastante perceptível no mapa, mostrando que ela é responsável por abranger uma região repleta de condomínios residenciais, observados no mapa pelas pequenas concentrações urbanas que têm seu limite no próprio traçado da linha, ou seja, o ônibus chega até a portaria dos mesmos, sendo assim, bastante utilizada por trabalhadores destes condomínios baseados em outras regiões da cidade e, também, por moradores que desejam se deslocar até o Centro, lugar atrativo pelo comércio e por concentrar grande parte das atividades do município.

- L L Linha 402 | Hopi Hari: Bastante extensa, esta linha realiza a ligação da Rodoviária com o Centro e, finalmente, com o parque temático Hopi Hari, passando por diversas fazendas, à beira da Rodovia dos Bandeirantes (SP-348). É muito utilizada por funcionários e clientes do parque e, em menor escala, por quem se desloca da cidade para a zona rural da parte oeste do município.

○ Linha 403 | Vila João XXIII e Jardim Três Irmãos: Esta é uma linha circular e realiza uma importante ligação entre bairros bastante povoados, a Vila João XXIII e o Jardim Três Irmãos, sendo utilizada para transportes diários, por estudantes e para desafogar as principais linhas que partem do Centro para os bairros, sendo uma alternativa para viagens de curta distância.

- Linha 404 | Santa Cândida: Uma das maiores linhas em extensão e em passageiros transportados, pois percorre um trajeto que interliga o Centro da cidade com o Bairro Capela, o mais populoso.

○ Linha 405 | São Joaquim: Esta linha segue a lógica das linhas 401 e 402, pois interliga o Centro com a zona rural. Neste caso, a linha 405 destina-se à região sul do município, abrangendo o Bairro Pinheirinho e o Condomínio São Joaquim. 


\section{Revista Nacional de}

Gerenciamento de Cidades

- Linha 406 | Capela e Palmares: Este é o percurso mais realizado nas viagens de ônibus urbanos em Vinhedo, pois a linha em questão realiza, assim como a linha 404, o trajeto CentroBairro Capela, transportando passageiros das duas principais regiões da cidade em termos populacionais.

○ L L Linha 407 | Jardim Mirian e Morada da Lua: Circular, tem como função ligar dois bairros populosos da parte norte da cidade: Jardim Miriam e Residencial Morada da Lua, abrangendo regiões importantes como o Centro.

○ Linha 408 | São Joaquim via CEIVI: Realiza um percurso parecido com a linha 405, porém, interligando também o Bairro Capela ao Condomínio São Joaquim, partindo, então, da parte oeste da cidade, passando pelo Centro, até a zona sul.

- Linha 409 | Capela e Paineiras: De trajeto semelhante às linhas 404 e 406, esta linha abrange mais regiões do Bairro Capela, conectando uma região periférica e bastante populosa ao Centro, por isso, bastante utilizada e vital para a mobilidade urbana de Vinhedo.

- L L Linha 410 | Vida Nova e São José: A terceira linha circular percorre regiões populosas e, assim como as outras, tem como principal intuito diminuir a concentração de passageiros nas principais linhas e interligar os bairros.

○ $\quad$ Linha 411 | Distrito Industrial: A linha circular mais recente a ser criada faz a ligação do Terminal do Bairro Capela ao Distrito Industrial, contribuindo, em grande parte, para o deslocamento de trabalhadores de suas casas às empresas e vice-versa.

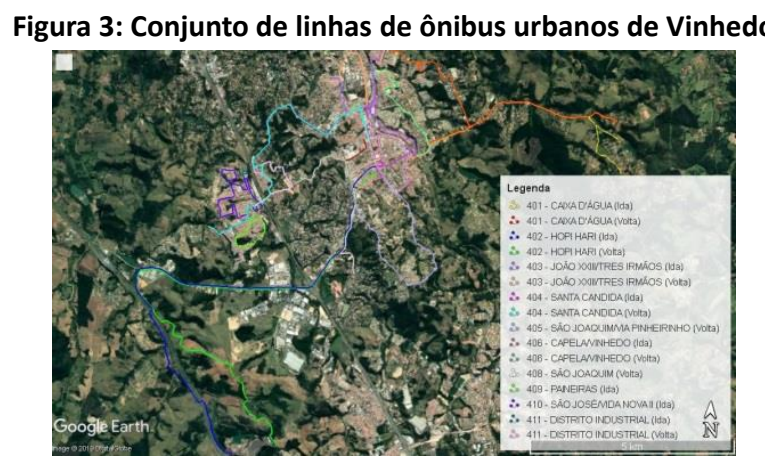

Fonte: Elaborado pelos autores, com base em Vinhedo (2019).

Percebe-se que algumas ruas e avenidas da cidade são privilegiadas com mais de uma linha de ônibus percorrendo-as, enquanto que outros locais não dispõem de tal facilidade.

Um fenômeno que acontece no município estudado e que merece enfoque especial é o da utilização de ônibus fretados para o deslocamento de grupos com destino e/ou itinerário comuns. Grandes empresas, colégios, universidades e afins utilizam-se deste tipo de transporte coletivo para substituir o uso do automóvel particular na ida ao trabalho de funcionários, ou no deslocamento de jovens e adultos para os estudos.

Em Vinhedo, destacam-se dois grupos que usam deste meio: a) ônibus fretados contratados por empresas: esta categoria é de financiamento privado, beneficiando especialmente funcionários 


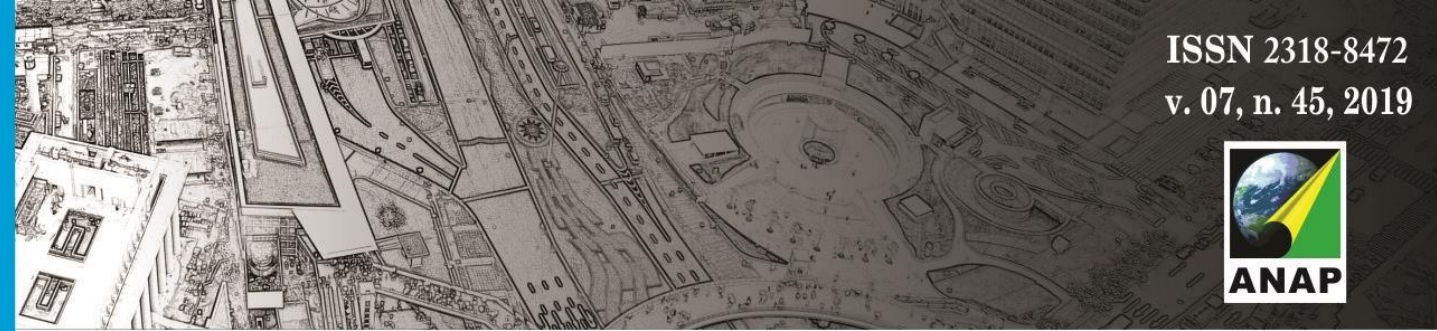

Revista Nacional de

Gerenciamento de Cidades

que deslocam-se diariamente ao Distrito Industrial. Pela ausência de veículos públicos, algumas companhias instaladas no Distrito pagam mensalidades a empresas de fretamento da região para que seus empregados tenham o transporte garantido; b) ônibus fretados contratados pelo governo municipal: esta categoria refere-se quase que exclusivamente ao transporte escolar e universitário, garantidos por Lei (VINHEDO, 2009).

\section{Considerações finais}

O presente estudo tratou da mobilidade urbana sustentável como solução a médio e longo prazos para otimizar o processo de crescimento da cidade de Vinhedo, que tem sua mobilidade baseada, como a maioria das cidades brasileiras, na lógica do transporte pelo automóvel particular.

Uma vez que a substituição total do automóvel é impraticável, depreende-se que uma alternativa inteligente e palpável consiste na "promoção e na complementaridade entre o transporte individual, os transportes coletivos e os modais suaves de locomoção, como a bicicleta" (GONÇALVES, 2007), aperfeiçoando os já existentes e inovando na criação de alternativas.

O próprio Plano Diretor Municipal vigente elenca estas prioridades, mas, como descrito acima, ainda há muito por fazer, como a integração entre as linhas de ônibus e as ciclovias, o aumento do número de quilômetros e da funcionalidade das ciclovias, fazendo com que tenham maior capilaridade nos bairros e integrem pontos distantes da mancha urbana com o centro, além do incremento das linhas de ônibus, que ainda são limitadas, privilegiam poucas regiões e não atendem bairros populosos de acordo com a demanda existente, conforme evidenciado na pesquisa.

O número tímido de linhas de ônibus, que em sua maioria privilegiam alguns pontos da cidade em detrimentos de outros, aliado à inexistência de traçados funcionais para a bicicleta, que deveriam estar integrados ao modal do transporte coletivo, evidencia que ainda há muito a ser fazer para que o transporte público de Vinhedo seja considerado sustentável.

Neste ponto, inovações como o aluguel de bicicletas nos terminais ou principais pontos de ônibus do município, auxiliado por aplicativos de celular, por exemplo, desponta como uma saída inteligente para preencher os vazios deixados pelas linhas urbanas.

Pelo fato de os maiores investimentos em transporte público de massa financiados pelo Governo Federal serem destinados às grandes cidades, a alternativa para Vinhedo passa por pequenas ações ligadas diretamente aos Poderes do município, e médias ações em conjunto com os municípios da Região Metropolitana de Campinas, também no sentido da inovação.

A partir disso, surgem soluções como o incentivo ao transporte por ônibus ao criar terminais de integração, bilhete único, reduzir as tarifas (a partir de 23 de março de 2019 o valor de tarifa passou a ser de $\mathrm{R} \$ 4,50)$, modernizar a frota, aumentar o número de linhas e a capilaridade dos itinerários e a realização de campanhas que incentivem a utilização de transportes alternativos ao automóvel particular. Salienta-se, ainda, que as linhas intermunicipais incrementam a 


\section{Revista Nacional de}

Gerenciamento de Cidades

mobilidade urbana via ônibus, ainda que sejam destinadas sobremaneira ao transporte metropolitano.

Posto isso, é certo que a cidade tem evoluído, especialmente nos últimos anos, rumo à sustentabilidade, mas a lógica do automóvel particular que moldou as políticas públicas de transporte é uma barreira que ainda precisa ser derrubada para que os munícipes tenham outras opções para o deslocamento cotidiano além do carro, incentivando a prática de exercícios físicos (inclusive através da caminhada), diminuindo a poluição causada pela emissão de partículas dos veículos motorizados no ar e reorganizando a utilização do espaço público.

Este dilema não se aplica somente ao caso do município abordado, mas à maioria das cidades brasileiras. Apenas com o ingresso da questão na agenda governamental a lógica vigente poderá ser rompida, rumo a um futuro próximo de mais qualidade e eficiência no transporte público e no acesso à cidade por todas as pessoas, permitindo, assim, o desenvolvimento sustentável.

\section{AGRADECIMENTO}

O presente trabalho foi realizado com apoio da Coordenação de Aperfeiçoamento de Pessoal de Nível Superior - Brasil (CAPES) - Código de Financiamento 001.

\section{REFERÊNCIAS BIBLIOGRÁFICAS}

ABDALA, Ivanilde Maria de Rezende; PASQUALETTO, Antônio. Índice de Mobilidade Urbana Sustentável em Goiânia como ferramenta para políticas públicas. Cadernos Metrópole, São Paulo, v. 15, n. 30, p. 489-511, Dezembro de 2013. Disponível em:

http://www.scielo.br/scielo.php?script=sci_arttext\&pid=S2236-99962013000200489\&lng=en\&nrm=iso. Acesso em: 07 mai. 2019.

ASSOCIAÇÃO BRASILEIRA DE NORMAS TÉCNICAS. NB 1350 - Normas para elaboração de plano diretor. Rio de Janeiro, 1991.

BOARETO, Renato. A política de mobilidade urbana e a construção de cidades sustentáveis. Revista dos Transportes Públicos - ANTP - Ano 30/31 - 2008 - 3o e 4o trimestres. 2008.

BRASIL. Mobilidade e desenvolvimento urbano. Brasília, Ministério das Cidades. (Gestão integrada da mobilidade urbana, 2). 2006.

BRASIL, Lei no 10.257, de 10 de julho de 2001. Regulamenta os arts. 182 e 183 da Constituição Federal, estabelece diretrizes gerais da política urbana e dá outras providências.

CARVALHO, Carlos Henrique Ribeiro de. Desafios da mobilidade urbana no Brasil. Brasília: Ipea, 2016.

CIDADES, Ministério das. Departamento Nacional de Trânsito - DENATRAN. 2014.

CRUZ, Maurício Feijó; FONSECA, Francisco César Pinto da. Vetores em contradição: planejamento da mobilidade urbana, uso do solo e dinâmicas do capitalismo contemporâneo. Cadernos Metrópole, São Paulo, v. 20, n. 42, p. 553-576, Ago. 2018 . Disponível em: 


\section{Revista Nacional de}

http://www.scielo.br/scielo.php?script=sci_arttext\&pid=S2236-99962018000200553\&lng=en\&nrm=iso. Acesso em: 07 Mai. 2019.

GIL, Antonio Carlos. Como elaborar projetos de pesquisa. 4. Ed., Atlas: São Paulo, 2002.

GIL, Antonio Carlos. Métodos e técnicas de pesquisa social. 5. Ed., Atlas: São Paulo, 2007.

GONÇALVES, Paula Margarida. Mobilidade Urbana Sustentável. 2007. Disponível em: https://www.academia.edu/2327663/Mobilidade_Urbana_Sustent\%C3\%A1vel. Acesso em: 08 mai. 2019.

IBGE. Perfil dos Municípios Brasileiros - 2015. Rio de Janeiro: IBGE, 2015.

MOZZATO, A. R.; GRZYBOVSKI, D. Análise de Conteúdo como Técnica de Análise de Dados Qualitativos no Campo da Administração: Potencial e Desafios. Revista de Administração Contemporânea, v. 15, n. 4, p. 731-747, Jul./Ago. 2011.

NASCIMENTO, Elimar Pinheiro do. Trajetória da sustentabilidade: do ambiental ao social, do social ao econômico. Estudos Avançados, v. 26, n. 74, p. 51-64. São Paulo, 2012.

RUBIM, Barbara; LEITÃO, Sérgio. O Plano de Mobilidade Urbana e o futuro das cidades. Estudos Avançados, v. 27 n. 79, p. 55-67, 2013. Disponível em:

http://www.scielo.br/pdf/ea/v27n79/v27n79a05.pdf. Acesso em: 08 mai. 2019.

SÃO PAULO, Decreto Estadual no 59.113, de 23/04/2013. Estabelece novos padrões de qualidade do ar e dá providências correlatas.

SÃO PAULO, Lei no 16.050, de 31 de Julho de 2014. Aprova a Política de Desenvolvimento Urbano e o Plano Diretor Estratégico do Município de São Paulo e revoga a Lei no 13.430/2002.

VERDEAZUL, Ranking do Programa Município. Disponível em <http://www.ambiente.sp.gov.br/municipioverdeazul/files/2011/11/RANKING.pdf>. Acessado em 05 mai. 2019.

VINHEDO, Lei Complementar no 66, de 17 de janeiro de 2007. Dispõe sobre Plano Diretor Participativo de Vinhedo - PDPV, e dá outras providências.

VINHEDO, Lei Ordinária no 2224 de 03 de julho de 1995. Dispõe sobre a destinação de espaços para ciclovias no município de Vinhedo, e dá outras providências.

VINHEDO, Lei Municipal no 3.270, de 16 de outubro de 2009. Institui, no âmbito da Administração Pública Municipal, o auxílio transporte aos estudantes de nível médio e superior.

VINHEDO, Prefeitura Municipal de. Ações de maior impacto social da Secretaria de Transporte e Defesa Social de Vinhedo. Disponível em <http://www.vinhedo.sp.gov.br/transportes-e-defesa-social/acoesde-maior-impacto-social/>. Acessado em 13/07/2016.

VINHEDO, Prefeitura Municipal de. Transporte coletivo (horários, itinerários e valores). 2019. Acesso em: 07 mai. 2019. 